\section{GP96 UNDERSTANDING PARENTAL EXPECTATIONS: THE STRUGGLES OF YOUNG PEDIATRICIANS (A SINGLE- CENTER EXPERIENCE)}

Georgiana Dragomir*, Laura Breban, Doris Burnaz, Teodora Adam. rd Pediatric Clinic, Emergency Children's Clinical Hospital, Cluj-Napoca, Romania

\subsection{6/archdischild-2019-epa.161}

Introduction As pediatricians, we rely considerably on the collaboration with our patients' parents, especially in outpatient care. Parental attitude towards medical advice is an important aspect in compliance with treatment. As young pediatricians in training, we sometimes encountered difficulties in understanding the particularities of parental mindset.

Purpose We aimed to explore several hypotheses that might lead to parental communication problems in our clinical practice. Also, we were interested in testing several factors we assumed influenced the attitude of caregivers toward their child's pediatrician, such as online mass media and online discussion groups.

Material and methods We carried out a cross-sectional survey addressed to parents that sought medical care for their child at Cluj-Napoca Emergency Children's Clinical Hospital. The parents were asked to fill in a printed or an online questionnaire with topics regarding their satisfaction after the medical consult. Through the questions, we tried to ascertain if they felt sufficiently informed and reassured about their child's condition and its course, if they needed more medical information about the treatment, if they had any reservations or mistrusted the prescribed treatment and how much of this influenced their compliance to the treatment. Through this, we aimed to understand the factors that make parents seek additional advice and where they go to find it.

Results Parental attitudes towards healthcare professionals seem to be influenced by internet-facilitated access to unprocessed medical information. Additionally, social media platforms likely represent the preferred framework to express opinions.

Conclusion We believe that understanding the expectations of our patients' caregivers is of utmost importance in order to gain their trust and to build a relationship based on mutual understanding. It is our opinion that complementary to medical education, young pediatricians could benefit from counseling and training in communication skills, ultimately becoming better professionals.

\section{GP97 OUT WITH THE OLD, IN WITH NEW: ARE WE STILL HESITANT IN IMPLEMENTING THE NEW NRP 7TH EDITION GUIDELINES TO DETERMINE INITIAL ENDOTRACHEAL TUBE INSERTION DEPTH FOR OROTRACHEAL INTUBATION?}

\footnotetext{
'Liqa ur Rehman*, 'Ahsan Rasool, 'Muhammad Shahid, 'Paula Cahill, ${ }^{2}$ Muhammad Zla, ${ }^{2}$ Uzair Khan, ${ }^{3}$ Riaz Ahmad, ${ }^{3}$ Naeem Shori, ${ }^{3}$ Muhammad Azam. ${ }^{1}$ Portiuncula University Hospital, Ballinasloe, Ireland; ' ${ }^{2}$ niversity Maternity Hospital, Limerick, Ireland; ${ }^{3}$ Wexford General Hospital, Wexford, Ireland
}

\subsection{6/archdischild-2019-epa.162}

Introduction It is quite challenging to insert $\&$ accurately position Endotracheal tube (ETT) in preterms. Mal-positioned ETTs are associated with complications like hypoxaemia, pneumothorax and right upper lobe collapse. In addition, adjustment of incorrectly placed ETTs requires additional handling of the infant, exposure to radiation and potentially increased risk of infection.
Aim To determine the chance of error of the ' $6 \mathrm{~cm}+$ birthweight' guide for calculating orotracheal-ETT position and further review the compliance with new 'tip-to-lip' guidelines on a national scale.

Method Three years retrospective data of pre-terms ( $<32$ weeks), requiring intubations, was collected from various hospitals. These hospitals used 'weight $+6 \mathrm{~cm}$ ' as a guide for orotracheal intubations. Using the Radiology database, chest Xray $\mathrm{PA}$ view of the first intubation, was considered as our standard to check optimal(T1-T3) and sub-optimal (above T1\&below T3) 'lip-to-tip' ETT position. Data was then analysed based on birth-weight and categorised as follows: 500 $1000 \mathrm{~g}$ and $1000-2000 \mathrm{~g}$.

The results then prompted us to conduct a telephonic survey of 18 hospitals across Ireland, providing level 1-3 neonatal services. Paediatrics/neonatal registrars were contacted by phone to answer a five question survey regarding the current practice of calculating 'Tip-to-Lip' insertion depth of ETT in pre-terms at their hospital.

Results We found that as birth-weight decreases, the percentage of error (when using 'birth-weight $+6 \mathrm{~cm}$ ' as a guide), increases. For birth-weight between 500-1000 g, our results showed a 58\% (22/38) error in tube insertion depth, this decreased to $50 \%(11 / 22)$ for neonates between 1000-2000 g.

The results from the telephonic survey were as follows:

\begin{tabular}{ll}
\hline Method of insertion & No. of hospitals \\
\hline Weight $+6 \mathrm{~cm}\left(6^{\text {th }}\right.$ ed. NRP) & 8 \\
NTL $+1 \mathrm{~cm}\left(7^{\text {th }}\right.$ ed. NRP) & 2 \\
$7^{\text {th }}$ ed. NRP (Consultant preference) & 6 \\
Don't know & 2 \\
\hline
\end{tabular}

Conclusion It is concluded using 'weight $+6 \mathrm{~cm}$ ' guide is less reliable and gives a higher chance of error in pre-terms $<1000$ g. Our survey showed that $55 \%$ of hospitals across Ireland still haven't adopted the NRP $7^{\text {th }}$ edition guidelines. The remaining hospitals though using NRP $7^{\text {th }}$ edition, only 2/8 have specified the method implemented.

Recommendation All hospitals should follow the new NRP 'Tip-to-Lip' insertion depth guidelines for oro-tracheal intubation to reduce the likelihood of error. There should be intradepartmental unanimity on implementation and documentation of specified methods to make it easier for future studies on accuracy of different methods. Practical simulation based sessions should be conducted in every hospital to propagate more awareness \& to enhance intubation skills of health care professionals.

\section{GP98 IL1- $\beta$ LEVELS AT PRESENTATION WITH PAEDIATRIC MILD TRAUMATIC BRAIN INJURY ARE HIGHER IN CHILDREN WITH PREVIOUS MILD TRAUMATIC HEAD INJURIES}

${ }^{1,2}$ Emer Ryan*, ${ }^{1}$ Lynne Kelly, ${ }^{2}$ Turlough Bolger, ${ }^{1,2,3,4}$ Eleanor Molloy. ${ }^{1}$ Discipline of Paediatrics, Department of Medicine, Dublin, Ireland; ${ }^{2}$ Tallaght University Hospital, Dublin, Ireland; ${ }^{3}$ National Children's Research Centre, Dublin, Ireland; ${ }^{4}$ Coombe Women's Hospital, Dublin, Ireland

\subsection{6/archdischild-2019-epa.163}

Aims To evaluate end components of the innate immune system, the inflammsome, in mild Traumatic Brain Injury (TBI) 